Volney José Berkenbrock. O mundo religioso. Petrópolis: Editora Vozes, 2019, 172p. ISBN: 978-85-326-6010-7.

\title{
Volney José Berkenbrock. O mundo religioso. Petrópolis: Editora Vozes, 2019, 172p. ISBN: 978-85-326-6010-7.
}

\author{
Matheus Landau de Carvalhol
}

Publicado pela Editora Vozes em 2019, o livro O mundo religioso, do doutor em teologia pela Rheinische Friedrich Wilhelm Universität de Bonn e professor do Programa de Pós-graduação em Ciência da Religião da Universidade Federal de Juiz de Fora, Volney José Berkenbrock, é uma obra estruturada em onze capítulos de tamanhos diferentes, não a partir das tradições religiosas em si, mas segundo o próprio fenômeno religioso e a maneira pela qual o mundo das religiões pode ser visto sob diversos pontos de vista. Com o objetivo de proporcionar aos leitores e leitoras "conhecimentos básicos sobre o mundo religioso. Sem preconceitos, sem a pretensão de defender esta ou aquela tradição, sem qualquer pretensão de destacar alguma religião em detrimento de outra, com a consciência de que nenhum tema será tratado exaustivamente." (p. 14), Volney indica, ao fim do livro, uma lista de obras historiográficas, religiosas e filosóficas, assim como de manuais de introdução a algumas tradições religiosas para aqueles que desejam se aprofundar nas temáticas do mundo religioso.

O autor inicia o primeiro capítulo ( $A$ presença das religiões no mundo) com o objetivo de elencar, percentualmente, as quatro maiores tradições religiosas do mundo (Hinduísmo, Budismo, Cristianismo e Islamismo) em número de adeptos, segundo a maneira pela qual ele procura definir "religião" ou "tradição religiosa" para responder à pergunta "Quantas religiões existem atualmente no mundo?" (p. 19). Em seguida, traça brevemente não apenas os perfis das pessoas que dizem não pertencer a qualquer religião, mas também as principais características das tradições religiosas com menos adeptos no mundo, i.e. Judaísmo, Xintoísmo, Confucionismo e Daoísmo. O teólogo aponta para o motivo segundo o qual Budismo, Cristianismo e Islamismo se expandiram mais do que as outras tradições religiosas em número de fiéis e abrangência geográfica, e ressalta as razões pelas quais o Islamismo se destaca neste cenário nos dias de hoje.

No começo do segundo capítulo ( $A$ presença das religiões no Brasil) o autor aponta para a dinâmica, no Brasil, entre mobilidade religiosa e maioria religiosa cristã, principalmente percebida pelos Censos Demográficos de 2000 e 2010. Volney destaca que "a diversidade religiosa brasileira é muito mais uma diversidade intracristã do que uma diversidade de religiões." (p. 28). Ao longo do capítulo, o teólogo aborda, brevemente, aspectos históricos, institucionais, sociais e psicológicos das maneiras pelas quais judeus, católicos, muçulmanos, hindus, evangélicos, budistas e praticantes de religiosidades afro-brasileiras e indígenas têm vivenciado suas respectivas tradições na história do Brasil até hoje.

No terceiro capítulo (Conceitos em torno da religião) Volney discute problemas de definição categórica e preconceitos implícitos nos usos dos termos "religião", "seita" e "filosofia de vida", sugerindo, ao final, uma definição de "religião" sem se esquecer de vários questionamentos teóricos e metodológicos que contribuem para os limites de aplicabilidade suficiente deste termo.

No quarto capítulo [Hipóteses sobre a origem da palavra "religião") o autor se debruça sobre as dimensões semânticas circunscritas às origens latinas da palavra "religião", assim como aos seus desdobramentos teológicos, temporais, ortodoxos e, sobretudo, ortopráxicos experimentados em ambientes cristãos.

\footnotetext{
1 Doutorando em Ciência da Religião na Universidade Federal de Juiz de Fora; Bacharel e Licenciado em História, Especialista e Mestre em Ciência da Religião pela Universidade Federal de Juiz de Fora. Contato: matheuslcarvalho@ig.com.br. Submetido em 09/08/2020; aceito em 05/11/2020.
} 
Volney José Berkenbrock. O mundo religioso. Petrópolis: Editora Vozes, 2019, 172p. ISBN: 978-85-326-6010-7.

No começo do quinto capítulo ( As teorias sobre a origem da religião) o teólogo apresenta duas possiveis categorias de resposta para a pergunta "Como surgiram as religiões?", discorrendo, em seguida, sobre um conjunto de teorias que tentaram respondê-la, a saber, as teorias evolucionistas, as psicológicas, as teológicas, as sociológicas, as fenomenológicas e as antropológicas, ressaltando suas respectivas linhas de pesquisa, assim como as características argumentativas e taxonômicas de cada uma delas.

Volney inicia o sexto capítulo (Escritos sagrados nas religiões) ressaltando a ausência de um único critério para se definir a sacralidade de um texto ou coletânea de textos reconhecidos como especiais, por algum motivo, por membros de determinada tradição, e apontando para vários razões que estabelecem as diversas Escrituras Sagradas da humanidade como tais. $O$ autor também elenca os diferentes processos de composição textual destas Escrituras, assim como os diversos estilos nos quais são elaborados. Ao longo do capítulo, o teólogo apresenta não apenas as maneiras pelas quais tradições religiosas organizam e classificam seus textos sagrados, mas também um breve resumo de algumas Escrituras Sagradas proeminentes nas tradições religiosas, como no caso da literatura védica das tradições hindus e a Bhagavad-Gi tā; o Tripițaka budista e - Dhammapada; os nove textos-fonte do Confucionismo e os Analectos, os escritos daoístas conhecidos como Três Cavernas e Quatro Anexos e o Dàodé jing; o Tanakh judaico e a Torá; o Novo Testamento e os Evangelhos, os livros sagrados do Islamismo e o Alcorão; os cinco principais tratados doutrinários do kardecismo e o Livro dos Espíritos, e os hinários do Santo Daime e o Hino Lua Branca, de Mestre Irineu.

O capítulo sétimo (As religiões e a tradição oral) é dedicado às religiões que não reconhecem nenhum texto como referência ou fundamento para a sua compreensão de fé, discutindo, inicialmente, como os indivíduos, os ritos e os mitos de uma religião se constituem nos aspectos pelos quais se mantém a tradição em religiões deste tipo, como o Candomblé e a Umbanda, tomados como ilustrações pelo autor ao longo do capítulo para a compreensão das dinâmicas estabelecidas entre estes mesmos aspectos.

Ao começar o oitavo capítulo (Os fundadores de religiões), Volney ressalta os desafios na identificação precisa de uma figura humana fundadora guardada pela memória de algumas tradições religiosas, assim como dúvidas sobre a existência empírica histórica de alguns destes fundadores. $O$ autor não apenas apresenta brevemente traços biográficos, com ênfase nos aspectos religiosos da vida dos fundadores de determinadas tradições religiosas, mas também destaca as principais características implícitas na maneira como cada um deles vivenciou individualmente sua própria religiosidade, e como esta foi subsequentemente proposta para possíveis seguidores, apontando para alguma literatura resultante da atividade religiosa da maioria dos fundadores abordados, como Amenófis IV no culto a Aton, Moisés no Judaísmo, Zoroastro no Masdeísmo, Lăozi no Daoísmo, Confúcio no Confucionismo, Siddhārta Gautama no Budismo, Jesus de Nazaré no Cristianismo, Mani no Maniqueísmo, Mohammed no Islamismo, Guru Nanak no Sikhismo, Alan Kardec no Espiritismo, Mestre Irineu no Santo Daime e Zélio de Morais na Umbanda.

Volney inicia o nono capítulo (Os sistemas religiosos e suas subdivisões) destacando os tipos de subdivisões internas que as tradições religiosas em geral comportam, principalmente nas quatro maiores da humanidade, assim como os motivos que levam a isso. Ao longo do capítulo, o teólogo dedica-se a breves narrativas dos desdobramentos históricos adquiridos por algumas tradições religiosas, destacando momentos de institucionalização da fé, de surgimentos de lideranças, de dinâmicas de conflitos internos, pressões externas e cisões institucionais, principalmente baseadas em divergências entre perspectivas ortodoxas dentro de uma mesma tradição. Para isso o autor utiliza como exemplos as igrejas persa, ortodoxa, romana, luterana, anglicana e presbiteriana no caso do Cristianismo, as correntes dos sunitas e dos xiitas no caso do Islamismo, as escolas Theravada, Mahāyāna, Vajrayāna, Zen e lamaísta do Budismo, as tradições hindus dos vaishnavas, dos śivaítas e dos śāktas, assim como o Jainismo. 
Volney José Berkenbrock. O mundo religioso. Petrópolis: Editora Vozes, 2019, 172p. ISBN: 978-85-326-6010-7.

O autor começa o décimo capítulo (As religiões e seus deuses) discutindo o desafio de se definir, univocamente, o que é uma divindade, seja quanto à sua presença ou sua ausência em algumas tradições religiosas, seja nos modos de gênero (masculino e feminino) em que pode ser cultuada, ou mesmo nas diversas formas de natureza em que pode ser considerada como tal, assim como de supostas etapas de uma evolução de sua elaboração. Volney discorre sobre a etimologia da palavra latina "deus" e também sobre a polissemia por ela adquirida em várias traduções vernaculares, chamando a atenção para várias compreensões de divindade monoteísta nas tradições judaicas, para as dinâmicas implícitas na compreensão cristã trinitária de Deus, para as características singulares e plurais de Alá, para as particularidades da "trimurti" e de outras divindades hindus mais proeminentes, assim como dos aspectos sui generis de Olorum no Candomblé.

No início do último capítulo (As religiões e o calendário), Volney destaca as principais características astronômicas e a importância do Judaísmo, do Cristianismo e do Islamismo na definição de contagens de tempo utilizadas no mundo até hoje. Em seguida, discute a dimensão religiosa e os desdobramentos históricos das festas do Natal cristão, do Ano Novo e da Páscoa.

De fato, é perceptível que a obra não se dedica a um inventário exaustivo de todas as manifestações culturais religiosas da humanidade, visto que não há referências, por exemplo, a religiosidades ameríndias pré-colombianas - exceto por alguns poucos exemplos do Brasil -, assim como de religiosidades nativas da Oceania, do norte da Ásia e de manifestações neo-pagãs europeias, dentre outras. No entanto, há uma visível atenção à polêmica de várias discussões metodológicas, principalmente com estudos de caso de várias tradições religiosas, aspecto no qual a obra se destaca por uma propedêutica eficaz. A maneira cativante de $O$ mundo religioso convida o leitor a questionamentos provocantes sobre questões mais gerais, porém não menos determinantes, para a compreensão das dinâmicas implícitas às religiões como um todo.

A ausência de certa exaustividade não obscurece, de modo algum, os insights pertinentes que o autor apresenta ao longo de toda a obra na tentativa de responder a certas questões fundamentais para a Ciência da Religião enquanto área acadêmica dedicada à compreensão do fenômeno religioso como uma irrevogável dimensão humana, principalmente no que toca a determinados aspectos taxonômicos e hermenêuticos inerentes ao ofício do cientista da religião.

Ao longo do livro há, recorrentemente, repetições desnecessárias de informações entre tópicos subsequentes do mesmo capítulo, com retomadas às vezes redundantes de dados. Entretanto, o autor consegue articular, de maneira muito bem sucedida, uma linguagem fluida com problemas complexos inerentes aos desafios apresentados na compreensão das tradições religiosas como um todo, fazendo com que o livro corresponda, suficientemente, às expectativas tanto de especialistas quanto de pessoas não inseridas em cada um dos temas e perspectivas acadêmicas abordados. Com efeito, $O$ mundo religioso é mais um capítulo genial e inusitado na compreensão do homo religiosus, seja como sujeito, seja como objeto da experiência religiosa. 